\title{
Kernos
}

Revue internationale et pluridisciplinaire de religion grecque antique

$4 \mid 1991$

Varia

\section{K. Dowden, Death and the Maiden. Girl's Initiation Rites in Greek Mythology}

\section{Pierre Bonnechere}

\section{(2) OpenEdition \\ Journals}

\section{Édition électronique}

URL : http://journals.openedition.org/kernos/324

DOI : 10.4000/kernos.324

ISSN : 2034-7871

\section{Éditeur}

Centre international d'étude de la religion grecque antique

\section{Édition imprimée}

Date de publication : 1 janvier 1991

Pagination : 338-339

ISSN : 0776-3824

\section{Référence électronique}

Pierre Bonnechere, «K. Dowden, Death and the Maiden. Girl's Initiation Rites in Greek Mythology », Kernos [En ligne], 4 | 1991, mis en ligne le 11 mars 2011, consulté le 21 septembre 2020. URL : http:// journals.openedition.org/kernos/324 ; DOI : https://doi.org/10.4000/kernos.324 
des chapitres si courts, si concis qu'on ne résiste par au désir de croire qu'ils sont insuffisamment écrits.

Mais une drôle de magie s'opère en cours de route, qui amène le lecteur à oublier, à la fin, les scrupules qui ont ralenti son chemin : l'itinéraire mythologique auquel l'a convié Bernard Deforge lui aura permis d'entrer en profondeur dans l'entonnoir du temps et de se retrouver, tout pensif et riche d'une longue réflexion, au cœur même de la question que lui avaient proposée les premières pages du livre.

Paradoxalement, on ne peut pas ne pas sortir enchanté de ce périple intelligemment mené, pour lequel l'A. s'est appuyé sur les recherches les plus récentes et les plus neuves, comme en témoigne la bibliographie. On oublie vite certains excès - le recours à Robert Graves, p. 133, par exemple - ou bien le souci trop évident de l'A. à vouloir rester pur de certaines tendances dans l'analyse du mythe, pour partager avec lui la richesse de son parcours. L'abondance de la documentation à laquelle il recourt et sa manière de la répandre sur la toile à grands coups de spatule finissent par créer un effet d'ensemble, auquel ne résiste pas le lecteur.

Pour ce qui est de la forme du volume, les Belles Lettres ont fait un bon travail d'éditeur : typographie claire et aérée (une ligne fut sautée à la page 20), correction de la langue (peu de coquilles - la note 43 de la p. 55 en a une, et il manque parfois l'accent d'un mot, comme aux p. 51 et 179 , mais ce sont des queues de cerise !). Il est dommage que l'on n'ait pas consenti à mettre les notes en bas de page, au lieu de les envoyer en séquence à la fin de chacune des parties et d'obliger ainsi le lecteur à un fastidieux va-et-vient.

Bref, voilà un livre qui, malgré ses apories, rendra service à tous ceux qu'intéresse la mythologie grecque. Un livre qu'on devrait trouver bientôt dans toutes les bibliothèques universitaires.

Jacques DESAUTELS (Laval)

Ken DOWDEN, Death and the Maiden. Girl's Initiation Rites in Greek Mythology, Londres-New Yok, Routledge, 1989, 1 vol., X+257 p., 8 cartes, ISBN 0-415-01263-5.

Ken Dowden jette de nouveaux éclairages sur les problèmes ressassés de l'initiation grecque, en tentant de remonter au-delà des premières sources écrites et archéologiques pour parvenir aux racines mycéniennes des mythes et rites si importants à l'époque archaïque. La perspective est donc différente de celle de ses prédécesseurs, dont le dernier en date est Pierre BRULÉ (La fille d'Athènes. La religion des filles à Athènes à l'époque classique. Mythes, cultes et sociétés, Paris, 1987. Annales littéraires de la Faculté de l'Université de Besançon, 363), auquel l'A. n'a pu se référer. Le terrain est parsemé d'embûches, 
en cette matière compliquée de la continuité cultuelle durant le moyen âge grec, aux confins brumeux de l'archéologie, de la philologie, de l'anthropologie et de la sociologie. L'A. cependant, habité d'une foi inébranlable, parvient honorablement à proposer des conclusions qui, si elles n'atteignent pas la certitude absolue, apportent de nombreuses et valables conjectures qui tendent à prouver l'origine au moins partiellement mycénienne de nombreux complexes mythico-rituels de nature initiatique. Le livre se présente comme la vérification d'une hypohtèse de base, au travers d'exemples importants que sont les cultes artémisiaques attiques (Brauron-Munychie), béotien (Aulis) et thessalien (Pagasae-Demetriae), les problèmes relatifs aux légendes d'Achille et de Leucippe, des Proetides, de Mélampous, d'Io, des Danaïdes et de plusieurs "histoires brèves" d'Achaïe et d'Arcadie. Bonne bibliographie sélective, index des noms, sujets et auteurs modernes.

S'il est vrai que les filles sont souvent mises à mal dans les légendes initiatiques, les garçons ne le sont pas moins, et il eût été plus opportun sans doute de traiter le problème sans distinction de sexe. De même, certaines légendes, comme celle des Érechthéides, des Cécropides, des vierges locriennes, des filles offertes en pâture aux monstres, auraient pu trouver ici un développement intéressant. Qu'à cela ne tienne, $K$. Dowden nous livre un texte intelligent et qui par son engagement fera progresser notre connaissance des initiations grecques.

Pierre BONNECHÈRE (Louvain-la-Neuve)

Gian Carlo DURANTI, Terzo numero binomiale di Euclide e terza civilità di Ammon-Zeus, Venise, 1988, 1 vol. 19,5 x 28 cm, 455 p.

Cet ouvrage est fondé sur la conviction de l'A. que le cosmos est scandé par de savants accords de principes duels. Le seul moyen de redécouvrir cette harmonie est d'abandonner la logique binaire traditionnelle pour ouvrir une nouvelle voie propre à rendre aux «idées de Justice» la place qui leur revient. Par conséquent, l'A se propose d'ôter à l'algèbre le rôle pilote qui lui est dévolu dans les mathématiques pour réintroduire les valeurs éthiques et esthétiques, substituant à une soidisant "objectivation de la Nature" un idéal de savoir comprenant, dans l'unité immense dont nous faisons partie, l'âme, l'art, la musique, le bien et, finalement, Dieu ! Les mathématiques apparaissent donc ainsi comme une philosophie, comme une conception exhaustive et intégratrice du cosmos.

Il est hélas difficile de suivre aveuglément l'A. sur la voie ambitieuse qu'il s'est tracée, tant ses convictions de départ semblent devoir l'emporter sur ce qu'on pourrait espérer découvrir par une méthode rationnelle. Ainsi, le travail entrepris par la critique moderne d'Euclide est-il balayé d'un trait de plume quand l'A. affirme, comme 